\title{
Dew condensation on desert beetle skin
}

\author{
J. Guadarrama-Cetina ${ }^{1, a}$, A. Mongruel ${ }^{2}$, M.-G. Medici $^{2,3}$, E. Baquero $^{4}$, A.R. Parker ${ }^{5}$, I. Milimouk-Melnytchuk ${ }^{2,6}$, \\ W. González-Viñas ${ }^{1 b}$, and D. Beysens ${ }^{2,6,7, c}$ \\ 1 Dept. Physics and Appl. Math., University of Navarra, Pamplona, Spain \\ 2 Laboratoire de Physique et Mécanique des Milieux Hétérogènes, Unité Mixte de Recherches 7636 Centre National de la \\ Recherche Scientifique - École Supérieure de Physique et Chimie Industrielles - Université Pierre et Marie Curie - Université \\ Paris Diderot, 10 rue Vauquelin, 75231 Paris, France \\ 3 Université de Nice, LPMC-CNRS-UMR 7336, 06108 Nice Cedex 2, France \\ 4 Dept. of Enviromental Biology, University of Navarra, Pamplona, Spain \\ 5 Department of Life Sciences, Natural History Museum, Cromwell Road, London SW7 5BD, UK \\ 6 OPUR, 60 rue Emeriau, 75015 Paris, France \\ 7 Service des Basses Températures, Commissariat à l'Energie Atomique-Grenoble \& Université Joseph Fourier, 17, rue des \\ Martyrs, 38504 Grenoble, France
}

Received 13 August 2014 and Received in final form 20 October 2014

Published online: 20 November 2014 C EDP Sciences / Società Italiana di Fisica / Springer-Verlag 2014

\begin{abstract}
Some tenebrionind beetles inhabiting the Namib desert are known for using their body to collect water droplets from wind-blown fogs. We aim to determine whether dew water collection is also possible for desert insects. For this purpose, we investigated the infra-red emissivity, and the wetting and structural properties, of the surface of the elytra of a preserved specimen of Physasterna cribripes (Tenebrionidæ) beetle, where the macro-structure appears as a series of "bumps", with "valleys" between them. Dew formation experiments were carried out in a condensation chamber. The surface properties (infra-red emissivity, wetting properties) were dominated by the wax at the elytra surface and, to a lower extent, its micro-structure. We performed scanning electron microscope on histological sections and determined the infra-red emissivity using a scanning pyrometer. The emissivity measured (0.95 \pm 0.07 between 8-14 $\mu \mathrm{m})$ was close to the black body value. Dew formation occurred on the insect's elytra, which can be explained by these surface properties. From the surface coverage of the condensed drops it was found that dew forms primarily in the valleys between the bumps. The difference in droplet nucleation rate between bumps and valleys can be attributed to the hexagonal microstructure on the surface of the valleys, whereas the surface of the bumps is smooth. The drops can slide when they reach a critical size, and be collected at the insect's mouth.
\end{abstract}

PACS. 68.03.Fg Evaporation and condensation of liquids - 87.19.-j Properties of higher organisms

\section{Introduction}

Harvesting water in arid or semi-arid regions is a challenge for life. Some insects such as beetles living in the Namib desert have developed a strategy to collect water drops $[1,2]$. When air is humid enough at night such that fog (and/or dew) can form, the beetle tilts its body forwards into the wind to collect the fog water in a manner that is well-known within some Tenebrionidae, and termed fog-basking [1]. Droplets form on the upper surface of the fused fore-wings (elytra) and roll down the beetles surface to its mouth parts. The elytræ of these water-collecting insects show surfaces that are either smooth or

\footnotetext{
a Present address: Facultad de Ciencias, Universidad Nacional Autónoma de México

b email: wens@unav.es

c email: daniel.beysens@espci.fr
}

with grooves or bumps (Fig. 1). However, in addition to fog droplets striking the elytra, the other possible mechanism by which water is extracted from the air to form large droplets, is dew droplets nucleation and growth on the elytræ. Laboratory studies have focused so far on the collection of fog droplets, either by spraying water or producing fog [3-5]. In a seminal paper [3], Parker and Lawrence highlighted the possible role of hydrophilic and hydrophobic microstructures to improve water drop collection. The droplets observed on Physasterna cribripes elytræ have a diameter 1 - $40 \mu \mathrm{m}$ and the water collection is assumed to be due to the hydrophilic property of the bumps and the hydrophobic characteristics of the valleys in between. Water accumulates on the top of the bumps and when its volume is sufficiently large, the droplets roll down along the hydrophobic surface towards the insect's mouth. Their study was the starting point for further investigation for 
nanomaterials with mixed wetting properties for improved water collection efficiency (see e.g. $[4,6,7]$ ).

However, further study on living beetles [5] have shown that tenebrionids that exhibit a fog-basking behaviour rather possess a uniform hydrophobic and smooth surface of their elytræ. Moreover, fog collecting efficiency on elytræ (of preserved beetles) showing different surface structures (smooth or with bumps), is not significantly influenced by these differences in hydrophobicity. Thus, the microstructure of the elytrae may not be the primary parameter for fog collecting but rather is secondary to the posture of the insect. Here, the beetle assumes a constant angle with the horizontal $\left(23^{\circ}\right)$. This angle is necessary for the fog drops to strike the surface and also to collect dew or fog water by gravity.

In all the above studies, there is some confusion between fog and dew phenomena [4]. We note that fog is formed of liquid water droplets with a diameter in the range of $10 \mu \mathrm{m}$. In contrast, dew involves the condensation of water vapour on a surface following a process of heterogeneous nucleation, which depends on the vapour supersaturation and on the wetting properties and the chemical and geometrical heterogeneities of the substrate, and further growth. One can make, however, the assumption that the collection of water drops is the same for both captured fog drops and condensed dew drops. It happens often that dew and fog form during the same night. It is a matter of fact that during dewy nights, dew starts to form first, with fog appearing only later, in the morning, when the atmosphere is at its coolest. The dew point temperature is reached when air is saturated at $100 \%$ relative humidity. Therefore it is reasonable to question whether dew can also form on an insect's back, since insects have no temperature regulation and the elytræ are disconnected from the insect's body by a layer of air that favours some thermal insulation. The climate where such insect lives (Gobabeb, Namibia from Ref. [5]) is characterised for year 2013 [8] by clear sky (only were recorded six rainy days, in March, September and December) and two seasons of high (60$80 \%$, September to March) and small (45-56\%, April to August) mean nocturnal humidity. The mean nocturnal temperature is about $18{ }^{\circ} \mathrm{C}$ when air is humid and $15{ }^{\circ} \mathrm{C}$ when it is dry. The number of days where dew can form corresponds typically to a temperature difference between air and dew point that does not exceed $10 \mathrm{~K}$, corresponding to relative humidity larger than $55 \%$ [9]. It should correspond for year 2013 to more than $60 \%$ of dewy nights. During condensation, the substrate temperature is typically between $1 \mathrm{~K}$ and $7 \mathrm{~K}$ below the dew point temperature [10].

It is the object of this study to determine whether dew can form on the elytræ of Physasterna cribripes. The elytræ of these water-collecting insects show surfaces that are either smooth or with grooves or bumps 0.5-1.5 mm apart, each about $0.5 \mathrm{~mm}$ in diameter and around 0.4 $\mathrm{mm}$ high (Fig. 1). In particular, we address the question of whether the particular infra-red emissivity, and the wetting and geometrical properties of the elytræ of Physasterna cribripes, (i.e. its very characteristic morphol-

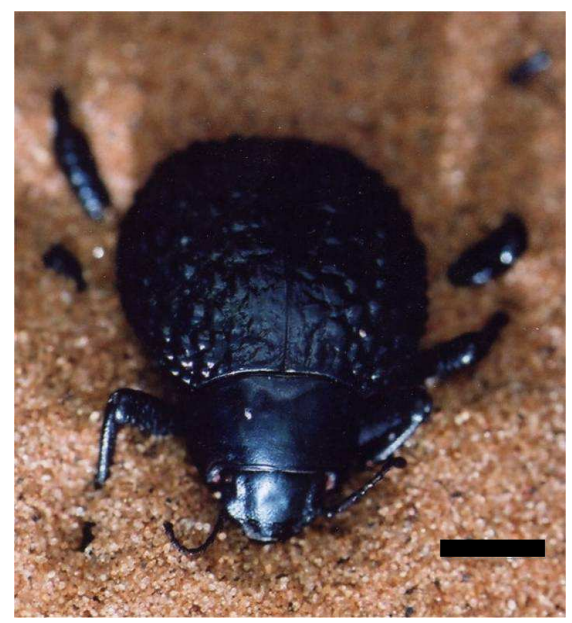

Fig. 1. Physasterna cribripes (Tenebrionidæ), female. The scale bar is $4 \mathrm{~mm}$.

ogy), are of particular interest for dew harvesting when compared to regular, smooth surfaces.

\section{Experimental investigations}

An elytra from a preserved specimen of Physasterna cribripes collected from the Skeleton Coast, Namibia, was dissected to provide two sections, each about $3 \mathrm{~mm} \times 7 \mathrm{~mm}$. Half of one section was studied in a Zeiss DSM 940A scanning electron microscope (SEM), and the remaining sections were used as a surface for dew condensation experiments.

\subsection{Elytra histology}

A schematic representation of a transverse section of elytra is shown in Fig. 2. For water condensation, the outer surface of the elytra (valleys and bumps) is most important. From the electron micrographs, the surface of the valleys only reveals a hexagonal periodic patterning with approximately $6 \mu \mathrm{m}$ period, and both the valleys and the bumps show some microsetæ (Fig. 3). The periodic structure is similar to the structure already reported by Parker and Lawrence [3]. The surface is coated with wax, however it is difficult to estimate whether the layer thickness of the wax varies from valleys to bumps, which would alter the surface energy and consequently the wetting properties. The wax on the exoskeleton of insects serves a protective function and reduces desiccation. The amount of wax is larger in animals which live in dry areas. The wettability properties depends on both the chemical properties of the wax and the geometrical (roughness) properties of the surface. The thickness of the layer of wax in Physasterna cribripes is approximately $15 \mathrm{~nm}$. 


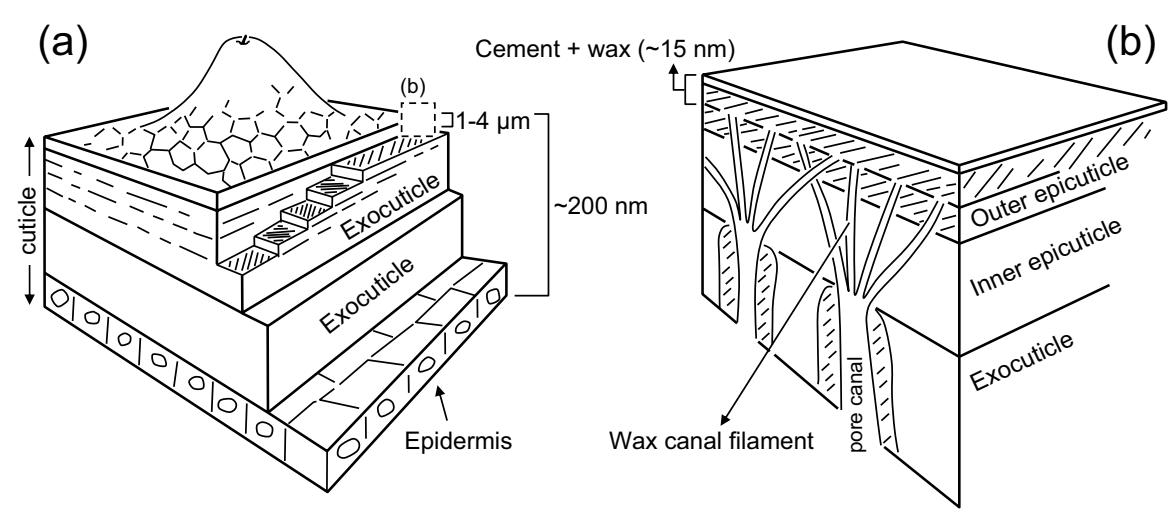

Fig. 2. Sketch of the elytra structure. (a) General cross-sectional view. (b) Details of exocuticle and epicuticle (from (a)).
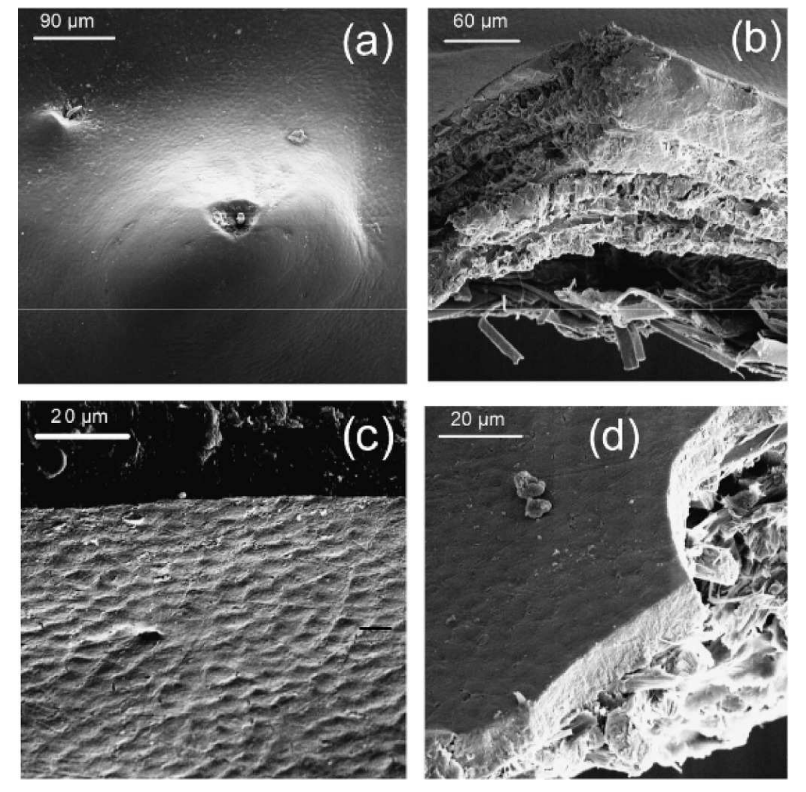

Fig. 3. SEM photos of elytra regions of Physasterna cribripes. (a) A bump and surrounding valleys. At the top of the bump, there is a small depression with a microseta. Another microseta is observed in the valley. The surface of the top of the bump is smooth; the surface of the valley contains an hexagonal structure (see (c)). (b) Transverse section through a bump. (c) Structured surface of the valley. (d) The smooth layer observed on the surface of the bump, which corresponds to the reticulated layer of cement plus wax, above the outer epicuticle.

\subsection{Infra-red emissivity}

In nature, surface cooling is insured by infra-red (IR) radiative cooling. The IR emissivity of the elytra was determined in the wavelength domain between 8-14 $\mu \mathrm{m}$ (the atmospheric window[11]) with a scanning pyrometer with temperature resolution of $\pm 0.5^{\circ} \mathrm{C}$. A section of cardboard with the same shape as the elytra and with known emissivity 0.81 was used together with the second part of the elytra. In a first set of experiments, the section of cardboard (experiment type (1)) and the elytra (experiment type (1') were attached with heat conductive grease onto a piece of glass with high emissivity (0.93). The glass itself was attached with heat conductive grease onto a disk made of electrolytic copper for high heat conduction. The disk made contact with the cold side of a Peltier element. The hot side of this Peltier element was connected to a temperature regulated water bath $\left( \pm 0.1^{\circ} \mathrm{C}\right)$. The room temperature was set at $22^{\circ} \mathrm{C}$ and that of the disk at $12{ }^{\circ} \mathrm{C}$. In this first set of experiments, the pyrometer did not detect any temperature difference between the elytra and the glass, thus indicating that the elytra has an emissivity close to that of the glass. In the further experiments, type (2) and (2'), a section of aluminium foil with low emissivity $(0.25)$ was used instead of glass. Here, the elytra was well detected by the pyrometer, in agreement with an emissivity much larger than the aluminium foil (Fig. 4).

The analysis of experiments type (1) and (2) in terms of emissivity gave the following values for the different surfaces investigated. The uncertainty was \pm 0.07 . Glass: 1; aluminium film: 0.28; cardboard: 0.76; elytra: 0.95 . The good agreement between the measured and expected emissivities for glass, cardboard and aluminium film confirms 
the accuracy of the measurements. The high value of the elytra emissivity conforms to that reported for Schistocerca gregaria, a desert insect called the bird grasshopper [12].

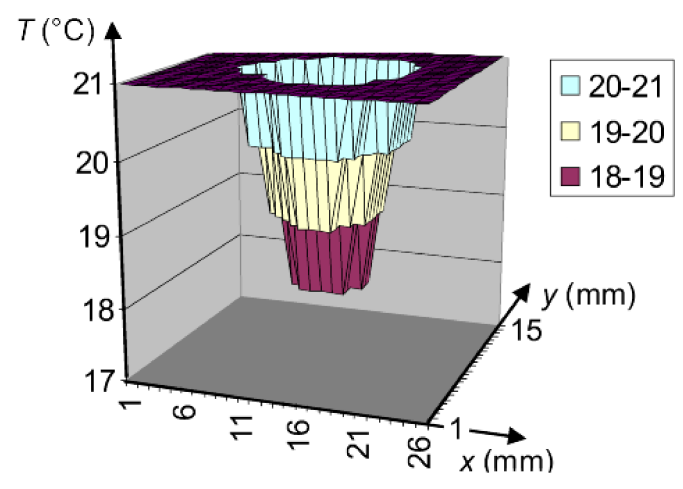

Fig. 4. Scanning pyrometer study on a section of elytra approximately $3 \mathrm{~mm} \times 7 \mathrm{~mm}$ attached to aluminium film (see text).

\subsection{Condensation}

The condensation experiments have to reproduce conditions typical of the desert conditions. However, for practical reasons, the experiment time has to be reduced, which corresponds to somewhat larger degree of supersaturation than found in an actual environment. The laboratory experiments will thus correspond to very favourable conditions and will somewhat emphasise the effects.

The second section of the elytra was attached with heat conductive grease onto the copper disk and placed inside the condensation chamber, which is cylindrical (diameter $2 L=10 \mathrm{~cm}$, height: $1 \mathrm{~cm}$ ). A flux of air saturated with water $(35 \mathrm{ml} / \mathrm{min}$ and $200 \mathrm{ml} / \mathrm{min})$ at room temperature $\left(23{ }^{\circ} \mathrm{C} \pm 0.3{ }^{\circ} \mathrm{C}\right)$, formed by bubbling air through ultra-pure water, was sent into the chamber through two holes ("nozzles") with $4.5 \mathrm{~mm}$ diameter. They are set at a chamber perimeter and perfectly aligned on a chamber diameter right under the level of the plane surface. The latter is slightly hollowed out like a channel over a length of $1 \mathrm{~cm}$. This considerably slows down the flow in the ratio hole/chamber cross-section $\left(\simeq 1.6 \cdot 10^{-2}\right)$ even before both flows meet at the expected stagnation point. Two other holes connected to the room are set on the chamber perimeter on a diameter perpendicular to the previous one. The maximum velocity is $u_{m}=0.2 \mathrm{~m} / \mathrm{s}$, corresponding to a nozzle output for the maximum flow rate $(200 \mathrm{~mL} / \mathrm{min}$.). The corresponding Reynolds number $R e=u_{m} L / \nu=750$ (with $\nu=1.4 \cdot 10^{-5} \mathrm{~m}^{2} / \mathrm{s}$ the air kinematic viscosity), a value much lower than the critical Reynolds number $\left(5 \times 10^{5}\right)$ where turbulence should occur. Flow even at the nozzles output for the largest flow rate is thus in the laminar regime. The elytra was positioned in this central region of the chamber. The copper disk temperature can be adjusted between $4{ }^{\circ} \mathrm{C}$ and $14{ }^{\circ} \mathrm{C}$ to provide water vapour condensation. The temperature measured on the elytra with a very thin thermocouple was the same than the copper disk temperature within at most $1{ }^{\circ} \mathrm{C}$.

Note that here the cooling process (conduction) is not the same as the radiative process that occurs during dew formation. However, the temperature is also nearly homogeneous on the surface of the elytra in both cases.

The development of the condensed pattern was observed by optical microscopy (magnification of $20 X$, resolution of $2 \mu \mathrm{m}$ ) using a CCD camera. The images were recorded on a computer for further analysis.

\section{Observations and analyses}

The development of water vapour condensation on the elytra was observed from the time the water vapour flux was sent into the chamber. We chose an area of observation where the two surface geometries (valley and bump) could be focused at the same time (Fig. 5). Applying the flux of water vapour, we found that water always condensed firstly on the most depressed parts of the elytra (valleys). This can be due to two reasons: (i) a thermal effect, the valleys being slightly colder due to their close vicinity with the copper disk and exhibiting a lower thermal exchange with the surrounding atmosphere that is at higher temperature; (ii) a difference in nucleation barrier (e.g. due to a different wettability and/or different nucleation sites and roughness); nucleation in the valleys can thus be promoted greater than on the bumps. The shapes of water drops in the valleys appear more irregular than on the bumps, corresponding to a smaller contact angle and/or a larger contact angle hysteresis [13]. Thermal and contact angle effects are investigated in the following experiments.

\subsection{Growth, contact angle and roughness}

The growth of water droplets on a plane surface obeys different regimes $[14,15]$. Nucleation of microdroplets proceeds first. The energy barrier for nucleation corresponds to the cost of formation of a vapour-liquid interface. It thus depends on the water contact angle $\theta$ on the surface. The barrier is maximum for $\theta=180^{\circ}$ (very hydrophobic surface) and minimum (zero) for $\theta=0^{\circ}$ (purely hydrophilic surface). In addition, geometric defects, which lower the vapour-liquid interface, also favour nucleation. Then nucleation proceeds preferentially on these nucleation sites that correspond to surface chemical and/or geometric irregularities. After having nucleated, droplets grow with radius $\sim t^{1 / 3}$ ( $t$ is time) and the drop surface coverage $\varepsilon^{2}$ increases on the surface. The surface coverage is defined as the ratio of surface occupied by condensed droplets to the total substrate surface. Droplets coalescence and then growth is accelerated. As the coalescence process lowers the surface coverage, a balance between the increase (by droplet growth) and decrease (by coalescence events) follows, where the drop surface coverage becomes constant 

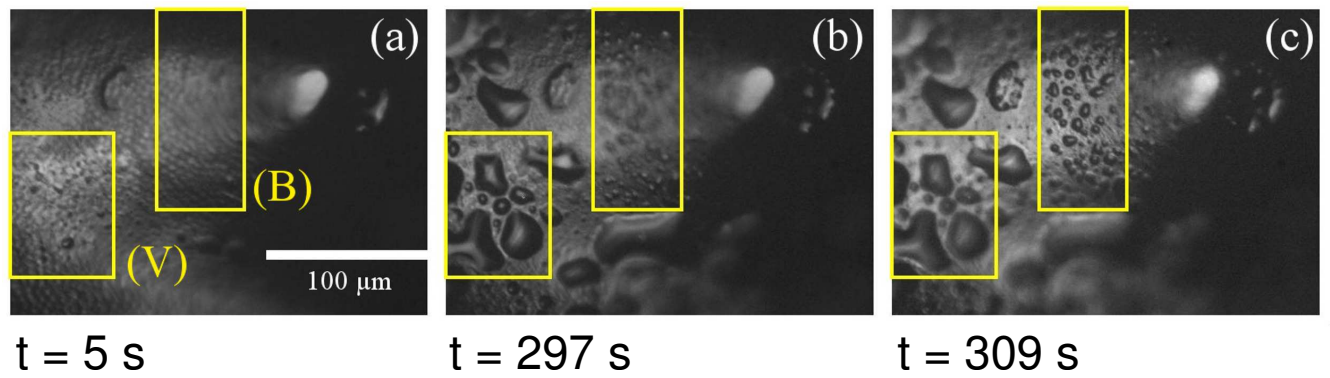

Fig. 5. Measurement of drop surface coverage (see text) in a valley (V) and a bump (B) of the elytra (flow rate: $200 \mathrm{ml} / \mathrm{min}$ ). (a) $t=5 \mathrm{~s}$, (b) $t=297 \mathrm{~s}$ (image is focused on region $\mathrm{V}$ ) and (c) $t=309 \mathrm{~s}$ (image is focused on region $\mathrm{B}$ ).

$\left(\varepsilon^{2}=\varepsilon_{\infty}^{2}\right)$, and droplet growth becomes self-similar (statistically scale invariant) with mean droplet radius $\sim t$. The constant $\varepsilon_{\infty}^{2}$ depends on the wetting properties (water contact angle and surface roughness) of the substrate [13]. These growth laws were indeed observed on both valleys and bumps, for the two flow rates as reported in Figs. 6ab.

On a smooth surface with small contact angle hysteresis, a mean contact angle (deg.) can then be obtained from the measurement of $\varepsilon^{2}$ in the self-similar, coalescencelimited stage of growth [13]:

$$
\varepsilon_{\infty}^{2} \simeq 1-(\theta / 200)
$$

The value of the contact angle should be between the advancing contact angle (the drops are growing) and the receding angle (drops that have coalesced). However, as there are far fewer drops in the latter case, this angle becomes close to the advancing contact angle. The analysis was performed on the valley and bump areas of two different elytræ exposed to the same room $\left(23{ }^{\circ} \mathrm{C}\right)$ and surface $\left(10{ }^{\circ} \mathrm{C}\right.$ ) temperatures, but to two different flow rates (set 1: $200 \mathrm{ml} / \mathrm{min}$; set $2: 35 \mathrm{ml} / \mathrm{min}$ ). The results for set 1 are shown in Fig. 5. The measurements of surface coverage $\varepsilon^{2}$ in the valley and bump areas are reported in Fig. 6. The data can be fitted to an empirical exponential function:

$$
\varepsilon^{2}=\varepsilon_{\infty}^{2}\left[1-\exp \left(\frac{t-t_{0}}{\tau}\right)\right] .
$$

Here $\varepsilon_{\infty}^{2}$ is the surface coverage limiting value in the self-similar growth regime, $t_{0}$ is the nucleation time and $\tau$ is the typical time to reach the self-similar growth regime. $t_{0}$ is contact angle and supersaturation dependent; $\tau$ depends on supersaturation and on water vapour flow rate.

The following values were found for the valleys:

\begin{tabular}{cccc}
\hline Set & $\varepsilon_{\infty}^{2}$ & $t_{0}(\mathrm{~s})$ & $\tau(\mathrm{s})$ \\
\hline 1 & $0.68 \pm 0.02$ & 0 & $100 \pm 10$ \\
2 & $0.76 \pm 0.01$ & 0 & $390 \pm 25$ \\
\hline
\end{tabular}

and for the bumps:

\begin{tabular}{cccc}
\hline Set & $\varepsilon_{\infty}^{2}$ & $t_{0}(\mathrm{~s})$ & $\tau(\mathrm{s})$ \\
\hline 1 & $0.36 \pm 0.01$ & $97 \pm 2$ & $63 \pm 5$ \\
2 & $0.40 \pm 0.01$ & $120 \pm 20$ & $\approx 400$ \\
\hline
\end{tabular}

The time $t_{0}$ is smaller for valleys than for bumps ( $100 \mathrm{~s}$ ) in both sets 1 and 2, regardless of the flow rate. Thus, the nucleation time for valleys is taken as the origin of time. This result indicates that nucleation is faster on the valleys than on the bumps. The typical times $\tau$ are comparable for both bumps and valleys (set 1: $\sim 80 \mathrm{~s}$; set $2: \sim 400 \mathrm{~s}$ ) but are larger in set 2 than in set 1 because of the lower flow rate.

The surface coverage limiting values were found to be larger in the valleys than on the bumps, for the two sets of data. Taking the mean values of $\varepsilon_{\infty}^{2}$ between set 1 and set 2, i.e. $0.72 \pm 0.04$ for the valleys and $0.38 \pm 0.02$ for the bumps, respectively, one obtains from Eq. 1: $\theta \simeq(64$ $\pm 8)^{\circ}$ in the valleys and $\theta \simeq(124 \pm 4)^{\circ}$ on the bumps. The surface of the valleys thus appears more hydrophilic than the bumps. However, this difference between valley and bump contact angles cannot be explained by a difference in surface coating as the valleys and bumps are both covered with wax. The only difference is that the surface of the bump is smooth while the valley surface exhibits a 6 $\mu \mathrm{m}$ period hexagonal patterning (Fig. 3). The patterning (i) favours nucleation, (ii) pins the droplets contact line, resulting in an increase of the contact angle hysteresis and an irregular droplet shape. The effects of patterning at this spatial scale are thus similar to the effects of lowering the water contact angle on a smooth surface.

\subsection{Thermal effects}

In order to test for differential thermal effects between valleys and bumps, we inverted the gradient of temperatures between the lowermost valley region and the highest (peak) part of the bump. To achieve this, we decreased the substrate temperature to $1{ }^{\circ} \mathrm{C}$ while streaming dry air $\left(23^{\circ} \mathrm{C}\right)$ to prevent water condensation. Then we rapidly increased the substrate temperature to $\approx 11{ }^{\circ} \mathrm{C}$ while simultaneously streaming humid air at the same temperature. The surface temperature of the valley was then larger than the bump temperature. However, as shown in Fig. 7, water vapour still began to condense in the valleys. This was in accordance with the largest contact angle at the bump location, where nucleation requires further supersaturation than in the valleys. 

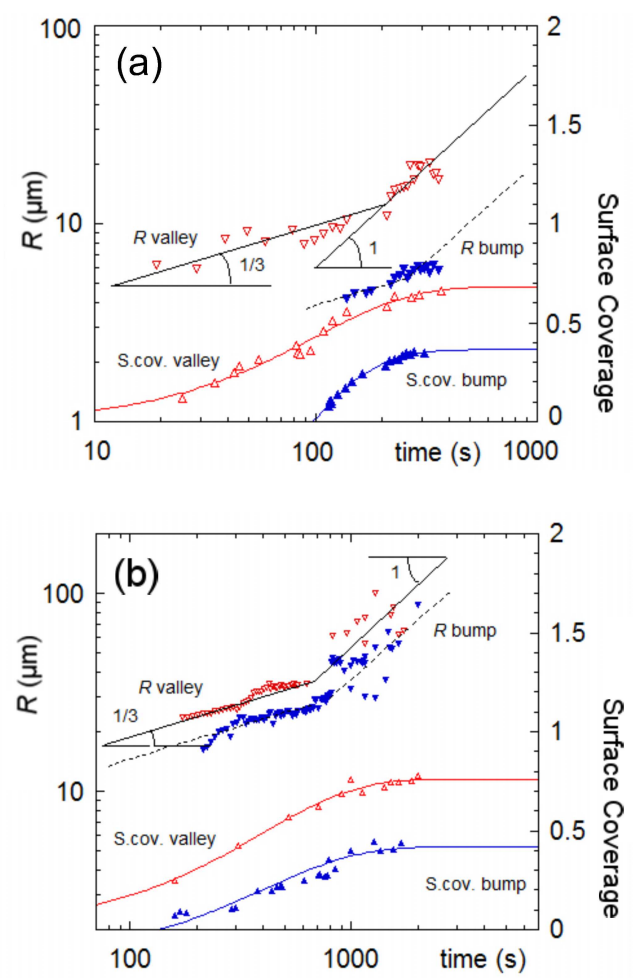

Fig. 6. Development of drop radius and surface coverage in a valley (open triangles (red)) and on a bump (filled triangles (blue)) for two different elytræ and flow rates. (a): set 1 (200 ml/min.); (b): set 2 (35 ml/min.).

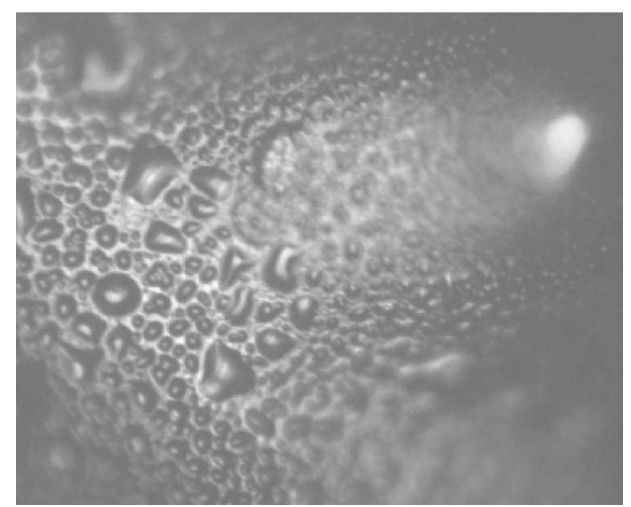

Fig. 7. A valley and a bump where the gradient of temperatures have been reversed; the water vapour still condensed first in the valley.

\section{Conclusions}

This study reveals specific properties of the beetle skin concerning dew water condensation. The high IR emissivity of the wax-coated elytra provides efficient radiative cooling. Higher droplet nucleation rate is found in valleys, where dew forms primarily. This is due to the hexagonal microstructure on the surface of the elytra. The latter provides more nucleation sites than on the bumps whose surface is smooth at the micron level. The role of these bumps, which are found on the backs of many other insects (but not in the fog basking species Onymacris unguicularis and Onymacris bicolor) remains thus unclear. They could serve as wind shields for the valleys, increasing there the dew yields. They can also be used to deter possible predators.

The dew collection properties of Physasterna cribripes is basically due to the high infra-red emissivity of wax. As insects are wax coated, this property should be shared by all of them, in particular those which, like the Onymacris unguicularis and Onymacris bicolor species, are known to harvest fog. Evidence that dew can be collected in addition to fog water on the backs of these beetles has not been examined yet in field experiments, where traditionally fog and dew phenomena have not been distinguished. This study reveals that dew collection is indeed possible on insect elytræ when the external conditions are favourable: clear sky and relative humidity larger than $55 \%$. These climatic conditions can be found in many coastal arid areas in the world.

The authors thank S. Zeine for help in the IR measurements. This work was partly supported by the Spanish MEC (Grant n. FIS2011-24642). JGC acknowledges financial support from the "Asociación de Amigos de la Universidad de Navarra".

\section{References}

1. Hamilton, W.J.; Seely, M.K., Nature 262, (1976) 284-285.

2. Seely, M.; Henschel, J.R.; Hamilton, W.J., South African Journal of Science 101, (2005) 570-572.

3. Parker, A.R.; Lawrence, C.R., Nature 414, (2001) 33-34.

4. Garrod, R.P.; Harris, L.G.; Schofield, W.C.E.; McGettrick, J.; Ward, L.J.; Teare, D.O.H.; Badyal, J.P.S., Langmuir 23, (2007) 689-693.

5. Nørgaard, T.; Dacke, M., Frontiers in Zoology 7, (2010) 23.

6. Dorrer, C.; Rühe, J., Langmuir 24, (2008) 6154-6158.

7. Zhai, L.; Berg, M.C.; Cebeci, F.C.; Kim, Y.; Milwid, J.M.; Rubner, M.F.; Cohen, R.E., Nano Lett. 6, (2006) 1213-1217.

8. http://www. wunderground.com/ (The Weather Underground, Inc.). Historical record (2013) for station id. 68106 of World Meteorological Organization.

9. Muselli, M.; Beysens, D.; Mileta, M.; Milimouk, I., Atmospheric Research 92, (2009) 455-463.

10. Beysens, D.; Muselli, M.; Nikolayev, V.; Narhe, R.; Milimouk, I., Atmospheric Research 73, (2005) 1-22.

11. Houghton, J., The Physics of Atmospheres (Cambridge University Press, 2002) 3rd edition.

12. Hunt, V.L.; Lock, G.D.; Pickering, S.G.; Charnley, A.K., Journal of Thermal Biology 36, (2011) 443-451.

13. Zhao, H.; Beysens, D., Langmuir 11, (1995) 627-634.

14. see e.g. Beysens, D., Comptes Rendus Physique 7, (2006) 1082-1100.

15. Briscoe, B.J.; Galvin, K.P., Phys. Rev. A 43, (1991) 19061917. 